\title{
A Study on Robot Technologies Used in Intelligent Systems with Nanotechnology Perspective*
}

\author{
Aylin TUTGUN ÜNAL \\ Maltepe University, Turkey \\ aylintutgun@maltepe.edu.tr
}

\begin{abstract}
In this research the robot technologies used in the integration of intelligent systems of the nanotechnology have been studied in 3 chapters: According to this research, various examples have been given (1) for the robot systems with human characteristics, (2) for robotizing of other organic living organisms, (3) for robot systems designed for other materials and the purpose used in different areas of the robot systems that are mentioned in the perspective of the human-computer interaction have been discussed.
\end{abstract}

Keywords: Nanotechnology, robot technologies, intelligent systems

\footnotetext{
* A part of the study was presented as a poster at 5th Nanoscience and Nanotechnology Conference 2009
} 


\section{INTRODUCTION}

Among the technologies that have oriented our epoch, the nanotechnology is appearing in almost every field of our life. According to David Bishop, it is quite impossible to find a field that won't be impressed by the nanotechnology (Bishop, 2005). In this regard, nanotechnology has been the cause of unbelievable developments in the computer systems that are in process from the past up to our days. Thanks to nanotechnology the computers, that one were almost of gigantic dimensions, became first desktop and later laptop devices and now they've become so small that they are pocket computers. Starting from this point we can say that elements show different behaviors in the nano dimension and further on they are showing extraordinary behaviors.

When it came out that elements that on ordinary time, do not reflect light and electricity, but when on nano dimension present opposite characteristics and that elements which not hard, in their natural state, become harder than diamond on the nano dimension, the nanotechnology was brought in sharp relief.

The word nano comes from the Latin word 'nanus' and its meaning is 'dwarf'. In the scientific field it is used as a technical measurement unit and even if it shows the one per billion of any unit, it is generally used together with the meter. Nanometer represents a length that is the one per billion of 1 meter. And this is approximately the lining up of 5 to 10 atoms. In our days, thanks to nanotechnology, it is possible to make forms in the lining up of the atoms that are forming the substance. If we have to define the nanotechnology we can say that it is a branch of technology that is the process that is realized considering the control of substance thanks to the scale of nano meter that means to molecular level, its measurement, modeling and arranging and other similar works that lead to the design and production of new materials, devices and systems.

Thanks to nanotechnology it will be possible to create very small robots, produced on extremely small scale and directed to various intents, in various fields. According to this, this technology is extremely important and it plays a role in between the disciplines and has an important role, as the nano robots are going to be used in different areas, such as in medicine and also in the military nano robots. With the nanotechnology it will be possible to produce robots on molecular dimensions and sensivity, to produce army of robots that will be controlled by a super computer and will form the immunity system of our bodies and also repair our cells on a molecular scale, it is theoretically possible robots that will stop aging and work on the DNA (Yağcrzeybek, 2008).

To develop a kind of nanoscale machine for different purposes is goal for scientist on this area. For example producing nanorobots against diabet and other type of medical issues (Cavalcanti et al., 2007, 2008).

When materials are reduced on the nano scale, we can see new superior characteristics that we cannot normally seen and this has caused a lot of new operations even in the military field. Nanotechnology can be used in the military field for producing smaller and lighter circuit elements, it can be used in the production of phantom planes that cannot be perceived by radars and even in the production of air vehicle with no man inside, this is 
theoretically possible. If electronic circuits and batteries can be produced by polymers the weight of military vehicles that are used will fall around $90 \%$. On the other side, it is inevitable that it will bring a great contribution in the military field, in producing intelligent uniforms with fabrics that can see, feel and hear (Bayındır, 2009).

In the perspective of nanotechnology, the robot systems that can be used in the intelligent systems have been studied under 3 chapters that are: (1) Robot Systems with human characteristics, (2) Robotizing other organic living beings, (3) Robot systems designed for other materials.

The aim of this research was to examine in the nanotechnology perspective some of the robot systems that can be used in intelligent systems orientated especially towards military fields and to study which how can these robot systems could be used in these fields. Starting from such a purpose, the robot systems of this study have been grouped in 3 different chapters according to the different areas where they can be used and for which they have been conceived.

\section{CLASSIFICATION OF ROBOTIC SYSTEMS}

Tutgun (2009) has dedicated robotic technologies used in intelligent systems into 3 groups in the previous study. Robot technology is important to classify because it is difficult to understand. According to Tutgun (2009), robot technology is almost impossible to examine without classification. From this point, this study has been divided into 3 groups of robot technology: (1) Robot systems with human characteristics, (2) Robotizing other organic living beings, (3) Robot systems designed for other materials.

\subsection{Robot Systems with Human Characteristics}

Scientists have created the first 'humanoid' robot that can mimic the facial expressions and lip movements of a human being. 'Jules' - a disembodied androgynous robotic head - can automatically copy the movements, which are picked up by a video camera and mapped on to the tiny electronic motors in his skin. Jules mimics the expressions by converting the video image into digital commands that make the robot's servos and motors produce mirrored movements. And it all happens in real time as the robot can interpret the commands at 25 frames per second. The project, called 'Human-Robot Interaction', was devised at the Bristol Robotics Laboratory (BRL), run by the University of the West of England and the University of Bristol ("Mail Online", 2008). After advances in humanenabled robots are produced for different purposes as well as ASIMO, SAYA etc.

\subsubsection{ASIMO}

Honda began developing humanoid robots in the 1980s, including several prototypes that preceded ASIMO. It was the company's goal to create a walking robot which could not only adapt and interact in human situations, but also improve the quality of life. The E0 was the first bipedal (two-legged) model produced as part of the Honda E series, which was an early experimental line of humanoid robots created between 1986 and 1993. This was followed by the Honda P series of robots produced from 1993 through 1997, which included the first self-regulating, humanoid walking robot with wireless movements. 
The research conducted on the E- and P-series led to the creation of ASIMO. Development began at Honda's Wako Fundamental Technical Research Center in Japan in 1999 and ASIMO was unveiled in October 2000.

ASIMO is the culmination of two decades of humanoid robotics research by Honda engineers. ASIMO can run, walk on uneven slopes and surfaces, turn smoothly, climb stairs, and reach for and grasp objects (Figure 1). ASIMO can also comprehend and respond to simple voice commands. ASIMO has the ability to recognize the face of a select group of individuals. Using its camera eyes, ASIMO can map its environment and register stationary objects. ASIMO can also avoid moving obstacles as it moves through its environment (“Honda Plaza Cem”, 2012).

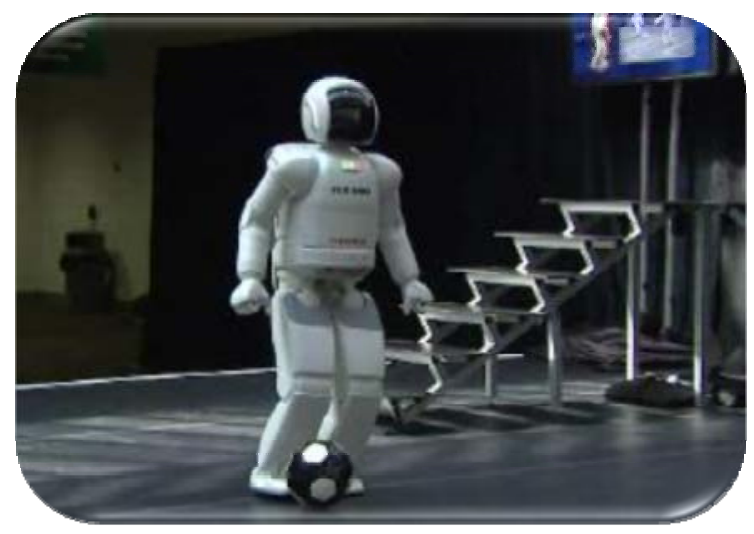

Figure 1. ASIMO

The all-new ASIMO is now advanced from an 'automatic machine' to an 'autonomous machine' with the decision-making capability to determine its behavior in concert with its surroundings such as movements of people. At the beginning of the development process, the following three factors were identified as necessary for a robot to perform as an autonomous machine ("Honda", 2011).

The technologies required to realize these capabilities were developed;

1. High-level postural balancing capability which enables the robot to maintain its posture by putting out its leg in an instant.

2. External recognition capability which enables the robot to integrate information, such as movements of people around it, from multiple sensors and estimate the changes that are taking place.

3. His capability to generate autonomous behavior which enables the robot to make predictions from gathered information and autonomously determine the next behavior without being controlled by an operator.

With these capabilities, the all-new ASIMO takes another step closer to practical use in an environment where it coexists with people. 
As development continues on ASIMO, today Honda demonstrates ASIMO around the world to encourage and inspire young students to study the sciences. And in the future, ASIMO may serve as another set of eyes, ears, hands and legs for all kinds of people in need. Someday ASIMO might help with important tasks like assisting the elderly or a person confined to a bed or a wheelchair. ASIMO might also perform certain tasks that are dangerous to humans, such as fighting fires or cleaning up toxic spills ("Honda Plaza Cem", 2012).

\subsubsection{Teacher Robots}

In a handful of laboratories around the world, computer scientists are developing robots like this one: highly programmed machines that can engage people and teach them simple skills, including household tasks, vocabulary or, as in the case of the boy, playing, elementary imitation and taking turns. So far, the teaching has been very basic, delivered mostly in experimental settings, and the robots are still works in progress, a hackers' gallery of moving parts that, like mechanical savants, each do some things well at the expense of others. Yet the most advanced models are fully autonomous, guided by artificial intelligence software like motion tracking and speech recognition, which can make them just engaging enough to rival humans at some teaching tasks ("Classroom Robotics", 2012).

Researchers say the pace of innovation is such that these machines should begin to learn as they teach, becoming the sort of infinitely patient, highly informed instructors that would be effective in subjects like foreign language or in repetitive therapies used to treat developmental problems like autism ("NDTV", 2010).

Several countries have been testing teaching machines in classrooms. South Korea, known for its enthusiasm for technology, is "hiring" hundreds of robots as teacher aides and classroom playmates and is experimenting with robots that would teach English (“NDTV”, 2010).

\subsubsection{Teacher Robot 'SAYA'}

Unlike more mechanical-looking robots like Honda Motor Co.'s Asimo, the robot teacher, called SAYA, can express six basic emotions - surprise, fear, disgust, anger, happiness, sadness - because its rubber skin is being pulled from the back with motors and wiring around the eyes and the mouth. In a demonstration, the robot's mouth popped open, its eyes widened and eyebrows arched to appear surprised (Figure 2). SAYA pulled back on its lips to make a smile, and said simple preprogrammed phrases such as "Thank you," while its lips moved, to express pleasure ("Daily News", 2009). 


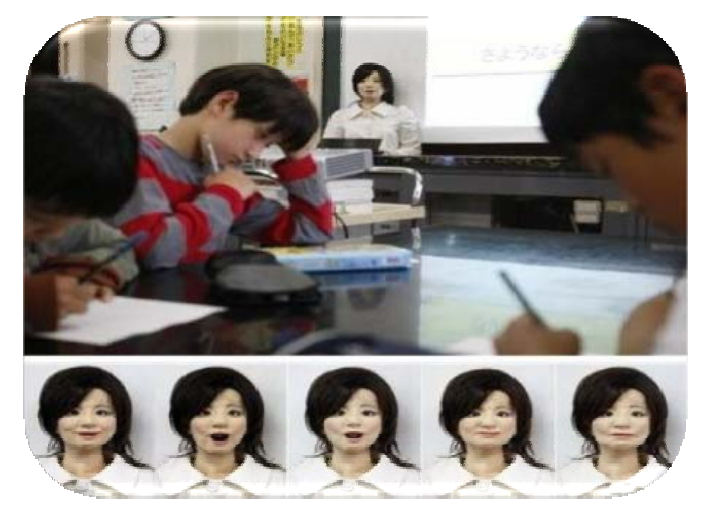

Figure 2. Teacher Robot 'SAYA'

First developed as a receptionist robot in 2004, SAYA was tested in a real Tokyo classroom earlier this year with a handful of fifth and sixth graders, although it still can't do much more than call out names and shout orders like "Be quiet" ("The Indiana Gazette", 2009).

\subsubsection{Teacher Robot 'Engkey'}

Engkey wheels around the front of a classroom at the Hagjeong Primary School in Daegu (Figure 3).

The egg-shaped robot asks the class - six fourth-grade students - to repeat English phrases and teaches them children's songs in English. But Engkey's voice is not its own. It is connected via teleconference to the Philippines, where a teacher conducts the class through a monitor. An image of a Caucasian woman appears on Engkey's LCD panel head, although she is not the teacher in the Philippines. Kim Mun-sang is director of the Intelligent Robotics Program at the government-funded Korea Institute for Science and Technology in Seoul. Engkey's creators say that students will determine how successful the robot is as a teacher. But they hope that someday all schools in South Korea will have a robot in the classroom ("Voice of America", 2011).

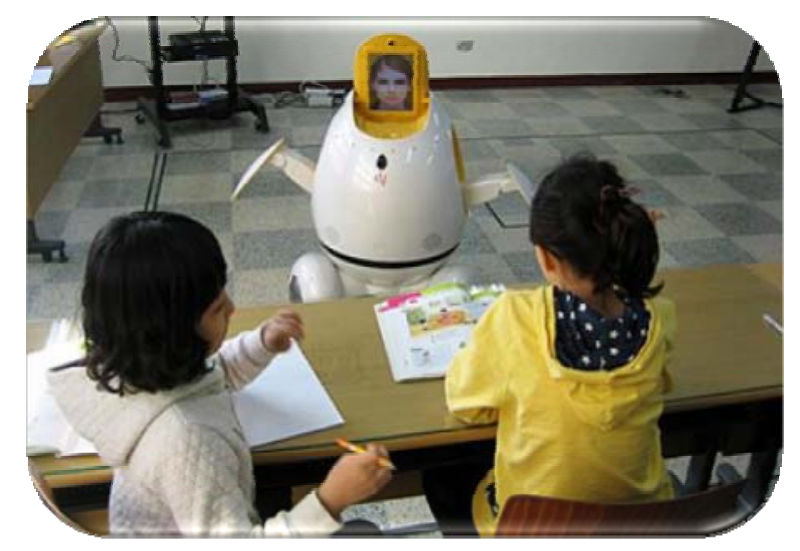

Figure 3. Teacher Robot 'Engkey'

\subsubsection{Teacher Robot 'RUBI'}


RUBI looks like a desktop computer come to life: its screen-torso, mounted on a pair of shoes, sprouts mechanical arms and a lunchbox-size head, fitted with video cameras, a microphone and voice capability (Figure 4). RUBI wears a bandanna around its neck and a fixed happy-face smile, below a pair of large, plastic eyes ("The New York Times", 2010).

Machine Perception Lab Co-Director Javier Movellan operates RUBI, a robot tutor equipped with an Intelligent Tutoring System that teaches preschool children colors, shapes and even Finnish vocabulary words ("UCSanDiego", 2008).

The University of Southern California robot used with autistic children tracks a person throughout a room, approaching indirectly and pulling up just short of personal space, like a cautious child hoping to join a playground game ("The New York Times", 2010).

In the San Diego classroom where RUBI has taught Finnish, researchers are finding that the robot enables preschool children to score significantly better on tests, compared with less interactive learning, as from tapes ("Seattle Education", 2010).

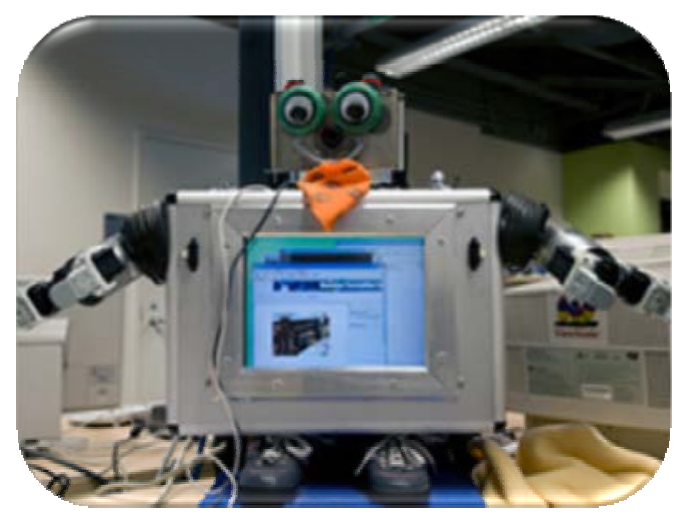

Figure 4. Teacher Robot 'RUBI'

\subsection{Robotizing Other Organic Living Beings}

Human Centered Robotics offers a proving ground where the most advanced ideas and design in intelligent systems, autonomous robots and Human-robot interface could be tested and put into operation. In other words, leading technology will emerge here and later transfer to many other application areas of intelligent systems and robots such as entertainment, healthcare, sport, rescuing and service ("Human Centered Robotics", 2012).

\subsubsection{Robot Fish}

In nature, fish has astonishing swimming ability after thousands years evolution. It is well known that the tuna swims with high speed and high efficiency, the pike accelerates in a flash and the eel could swim skillfully into a narrow hole. Such astonishing swimming ability inspires us to improve the performance of aquatic man-made robotic systems, namely Robotic Fish (Figure 5). Instead of the conventional rotary propeller used in ship or underwater vehicles, the undulation movement provides the main energy of a robotic fish. The observation on a real fish shows that this kind of propulsion is more noiseless, 
effective, and maneuverable than the propeller-based propulsion. The aim of our project is to design and build autonomous robotic fishes that are able to reactive to the environment and navigate toward the charging station. In other words, they should have the features such as fish-swimming behavior, autonomously navigating ability, cartoonlike appearance that is not-existed in the real world ("Human Centered Robotics Group at Essex", 2010).

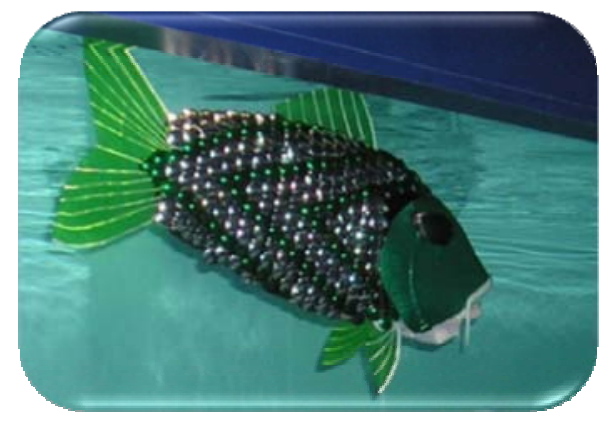

Figure 5. Robot Fish

\subsubsection{Robot Fly}

A life-size, robotic fly has taken flight at Harvard University (Figure 6). Weighing only 60 milligrams, with a wingspan of three centimeters, the tiny robot's movements are modeled on those of a real fly. While much work remains to be done on the mechanical insect, the researchers say that such small flying machines could one day be used as spies, or for detecting harmful chemicals ("Technology Review”, 2007).

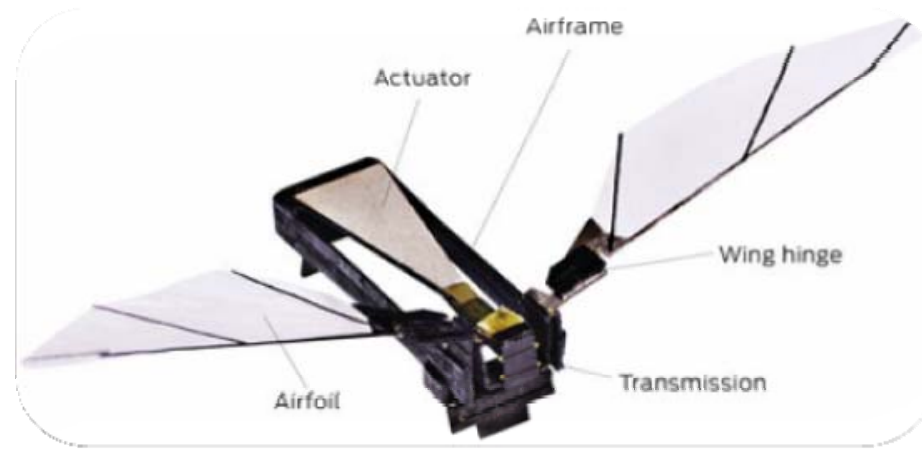

Figure 6. Robot Fly

\subsubsection{Robot Bird}

The robot bird, which has been given the to-the-point name of Smart Bird, was shown off by robotics company Festo (Figure 7). The Smart Bird design is based on a real life bird, a herring gull, which is able to take off, with the help of an on board motor. Then the wings begin to flap. Once they get beating at the right speed, the wings begin to imitate the way that real birds fly. The front edge of the wing twists, and generates thrust, and the tail acts the same way that a rudder would, steering the bird in different directions. Who knows, maybe this remote controlled gull will be the spy boot of the future. One, slightly more pragmatic goal may be to co-opt the wing technology to create what are known as 'stroke 
wing generators', which can use this same motion in order to generate power from water. So, this little bird may actually be green ("PHYS.ORG", 2011).
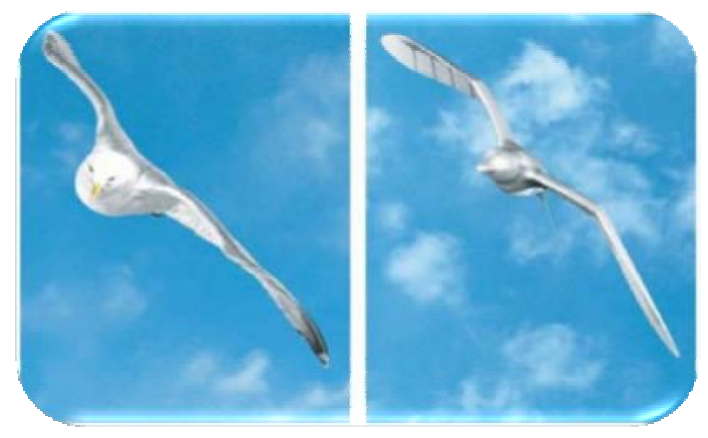

Figure 7. Robot Bird

\subsubsection{Robot Snake}

This monstrous electro-mechanical beast named Titanoboa weighs more than a ton, and its makers plan to eventually cover it with what they call 'a more polished-looking skin', and if all goes well, [it will] be able to move underwater (Figure 8).

The Titanoboa project is an exercise in alternative forms of propulsion and power applications in transport. The purpose is to showcase this experiment by harnessing and enlarging the mesmerizing movement of the snake. The huge serpent has undeniable appeal as a surreal mechanical beast that moves in a seemingly magical way over land and will glide stealthily through the water. One or more participants will eventually interact with the piece by riding it or for the more ambitious, driving it. The complex control needed to properly move hundreds of individual parts will necessitate a skilled operator who has taken time to become at one with the serpent ("Mashable Tech", 2012).

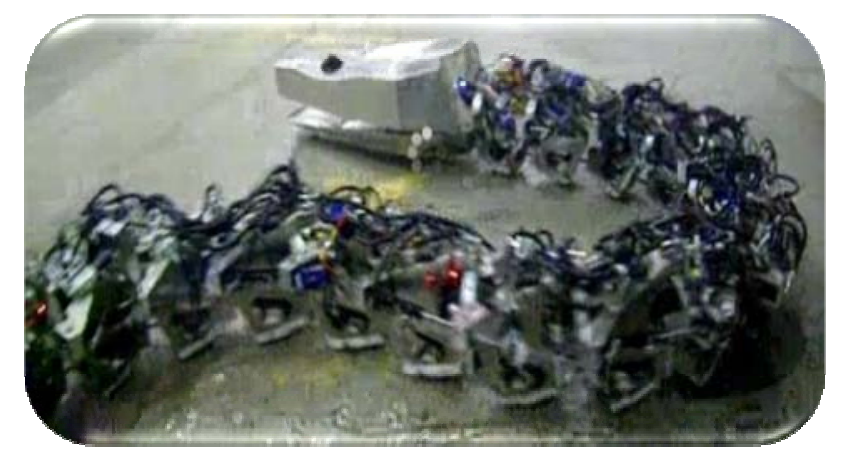

Figure 8. Robot Snake: Titanoboa

\subsection{Robot Systems Designed For Other Materials}

Cost-effective nanotechnology-based water repellent treatments for clothing fabrics are now commercially available. The effectiveness of these durable water repellent (DWR) fabric treatments were evaluated for application to military uniforms. The addition of a non-wicking finish to clothing fabric negatively impacts comfort in hot and humid 
environments. Clothing comfort may be improved by refining the DWR fabric treatment process to retain wicking properties on the fabric inner surface (Gibson, 2008).

On the other hand, textile products, which are made of natural, synthetic or blended fibers, are sensitive to contamination and growth of pathogenic microorganisms. Therefore a great consumer demand for hygienic products has dramatically increased the use of antimicrobial substances on textiles (Mucha, Hoefer et al., 2002). Ionic silver compounds, a well-known antimicrobial agent which is capable to inhibit and kill bacteria and fungi (Klasen, 2000), is unique in comparison with other antimicrobial agents because it has no toxicity and carcinogenic activities (Stillman et al., 1994). For these reasons, Ureyen, Cavdar et al. (2009) studied on a model in their work. In their work antimicrobial finishing agent for textile fabrics were developed and applied cotton, PES and modal fabrics. Antibacterial efficacy of the treated samples were tested and compared before and after laundering. Test results showed that treated fabric samples preserved their strong antibacterial activities after 20 laundry cycles.

The scientists say that by 2025 , combat gear will have evolved so that soldiers will be able to sense an oncoming attack, change chameleon-like to blend in with their surroundings and make temperature adjustments ("BBC News", 2012).

Nanotechnology will play a major role in the development of the new generation of army uniforms and equipment (Figure 9). This is the science of manipulating particles smaller than 100 nanometers, or one-hundredth of the width of a human hair strand, to create new materials.

By changing the properties of materials, such as by introducing tiny nanoparticle reinforcements into polymers, nanotechnology will enable such advances as making helmets $40-60 \%$ lighter and creating tent-fabric that repairs itself when it rips ("BBC News", 2012).

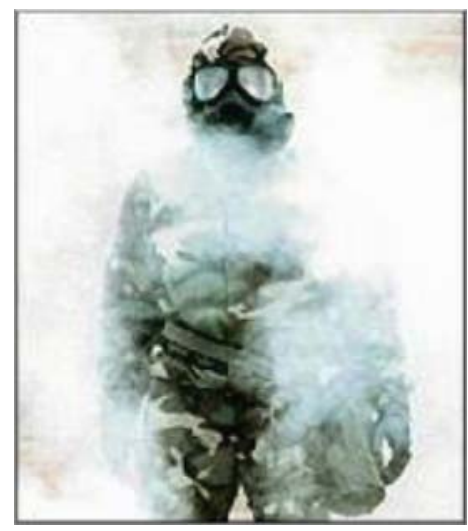

Figure 9. Lighter, Breathable Uniforms

None of the water-repellent treatments significantly affected the breathability, air flow resistance, or pore size of the BDU fabric (Gibson, 2005). It was found that the standard 
Battle Dress Uniform (BDU) fabric can be modified with very effective water-repellent treatments.

Soldiers' duty and combat uniforms can be made water-resistant and retain the same air permeability and breathability" properties as the untreated wicking fabric. Following a separate field trial using combat uniforms with and without a DWR (durable water repellent) treatment, it was found that these treatments decreased the comfort of the uniform in hot environments. The differences between the comfort of the control uniform and those treated with the DWR treatments are probably not due to intrinsic differences in the air permeability or the water vapor diffusion resistance (breathability) of the fabric. It is more likely that the non-wicking behavior of the fabric was responsible for perceived comfort differences, per comments from the field trial, and by analysis of wicking/comfort properties contained in this report. Some of the DWR treatments are available as coatings on just one side of the fabric. The outer layer of the fabric can be made water-repellent, while the inner surface retains its wicking characteristics. Based on comments from the field trial, and modeling results, such asymmetric treatments would improve the comfort of DWR treatments on military duty uniforms as compared to full water-repellency on both sides of the fabric. (Gibson, 2008).

With the advent of nanotechnology, chemical protective over garments, which shield soldiers against hazardous chemicals and deadly micro-organisms, will enter a new phase of development. According to BBC News (2012), the new uniforms will be breathable and $20 \%$ lighter in weight than the standard battle-dress over garment. For the Army, developments across the commercial sector mean potential corporate partnerships and the possibility of adapting uses of nanotechnology for military purposes.

\section{CONCLUSION AND DISCUSSION}

Parallel to the development of nano materials there is an intensive discussion about safety aspects of nano scaled and nano modified products (Arnim, Ewert et al., 2009). At this point, applications developers who apply human-factors principles and processes are producing exciting interactive systems. But, understanding the physical, intellectual and personality differences among users is vital.

In this study, Robot technologies have been examined in three chapters. According to this research, various examples have been given for the robot systems with human characteristics, for robotizing of other organic living organisms, for robot systems designed for other materials. It is interesting that teacher robots teach lessons to the students at the real time of instruction but how much were taken into account the human factor and the personality differences?

Engkey's creator's hope that someday all schools in South Korea will have a robot in the classroom. According to Shneiderman (1997), some people dislike computers or are made anxious by them; others are attracted to or are eager to use computers. Often members of these diverged groups disapprove or are suspicious of members of the other community. Even people who enjoy using computers may have very different preferences for 
interaction styles, pace of interaction, graphics versus tabular presentations, dense versus sparse data presentation, step-by-step work versus all-at-once work, and so on. These differences are very important.

From this point of view, is it argumentative that how healthy it would be to learn from robot teacher? It is aimed that robot teachers are included in the courses not with the purpose of substitution with teachers but for providing support. Even so, most of the issues mentioned above should be discussed for the convenience of real-time learning environment. Apart from the fact that the courses which is supported with robot teacher would not be beneficial for students who do not like to learn through technology, students who are interested in technology would require different interaction styles. Are these points considered through the perspective of an educationalist in the design of robot interface? That Robot SAYA reflects different feelings and variety of facial expressions cannot meet the variety of mentioned interaction. Therefore, since the interaction would be limited with students even though as a support, its danger for students is indisputable. On the other hand, it is nearly impossible to create a robot which would react to individual differences of students. As a result, students have different individual characteristics and learning styles. When even only this point is considered, robot teacher would not appeal to all students. While we are in the aim of addressing all students in this training and education environment, how many percent of the students the robot teacher would address them?

Robots produced for different tasks modeled on other organic species have the potential to be able to achieve the vital tasks. This situation gives hope for the future. The planned tasks are; detecting harmful chemicals, power applications in transport, co-opt the wing technology to create what are known as 'stroke wing generators', design and build autonomous robotic fishes that are able to reactive to the environment and navigate toward the charging station.

Nanotechnology is being rapidly formed as the industrial revolution of $21^{\text {st }}$ century. Nanotechnology would influence every step of life from food products we consume to the clothes we wear, from the drugs we use to the power of our computer, from the automobiles we drive to the houses in which we live. In a long term, the effect of nanotechnology would be as distinctive as steam power, electricity or transistors.

The importance of nanotechnology is profound for the military field. Another reason of nanotechnology is to create new generation uniforms for soldiers. One of the most important military applications of nanotechnology in a short-term is to create and manufacture smart uniforms in order to decrease loss of soldiers. Because nanotechnology processes the level of resistance by considering classical visible physical deficiency. The aims of nanotechnology military institute would grow in order to "protect and survive".

The Institute for Soldier Nanotechnologies at MIT which was founded in Boston, USA in 2000 plans to render military uniforms smart by means of nanotechnology within 15 years. By way of integrating flexible and washable nanosensors and apparatus within the fabric, uniforms will gain new dimensions; after all they will see, hear, feel, issue 
commands and generate energy. The issue which must be expressed here is that nanodevices would be so small that it would not hamper the person who wears it. This smart uniform which will determine chemical and biological agents will also make cardiac message and bring the soldier back to life. It will convey all the information of soldiers who are injured in the battle field through wireless line, and provide intervention in a short time when required. When necessary, the uniform would transform into a hard armor and obtain the energy required by the soldier from the sun.

\section{SUGGESTIONS}

Some suggestions about robot technologies used in intelligent systems have been given in this section.

1. The scope of the study about robot technologies used in intelligent systems can be increased with more examples.

2. Other future research can be examined under three chapters used in this study.

3. Individual differences can be taken into consideration when designing the teacher robot interfaces.

4. The educator team should participate in the design of robot teacher.

5. The number of people must be increased who know nanotechnology to fulfill difficult and important tasks. 


\section{REFERENCES}

Arnim, V., Ewert, B. et al. (2009). Methods, effects and safety aspects for nanostructure based functionalization of Technical Textiles, 5th National Nanoscience and Nanotechnology Conference, Anadolu University Publication No: 1906, İleri Teknolojiler Araştırma Birimi Yayınları [Advanced Technologies Research Unit Publications], No:1, Page 409.

Bayındır, M. (2009). "Nano Teknoloji Devrimi Geliyor" [Coming Nanotechnology Revolution], journal of 'Meşale', http://www.fen.bilkent.edu.tr/ mb/dokumanlar/NanoteknolojiDevrimiGeliyor_TE D_Mesale.pdf retrieved on April 9, 2009

BBC News (2001). Nanotech future for soldiers. http://news.bbc.co.uk/2/hi/science/nature/1554130.stm retrieved on May 2, 2012.

Bishop, D. (2005). Overview. Bell Labs Technical Jounal, 10(3):1-3.

Cavalcanti, A. et al. (2007). Recent Patents Nanotechnol, 1, 1-10.

Cavalcanti, A. et al. (2008). Nanomedicine: Nanotechnology, Biology and Medicine, 4, 127138.

Classroom Robotics (2012). More Robot Teachers. http://classroomrobotics.blogspot.com/2012/01/more-robot-teachers.html retrieved on April 30, 2012.

Daily News (2009). SAYA, Japan's robot teacher, can smile and scold, but don't fire those substitutes yet. http:/articles.nydailynews.com/2009-0311/news/17918779_1_human-robot-SAYA-teacher retrieved on April 20, 2012.

Gibson, P. (2005). Water Repellent Treatments on Battle Dress Uniform Fabric. U.S. Army Natick Research, Development, and Engineering Center Technical Report, Natick/TR05/023. retrieved on April 12, 2012.

Gibson, P. (2008).Water-Repellent Treatment On Military Uniform Fabrics: Physiological And Comfort Implications. Journal of Industrial Textiles, July 2008 vol. 38 no. 1, 4354 .

Honda (2011). News Releases 2011. http://world.honda.com/news/2011/c111108All-newASIMO/ retrieved on June 27, 2011.

Honda Plaza Cem (2012). ASIMO. http://www.hondacem.com.tr/asimo.php retrieved on April 27, 2012.

Human Centered Robotics (HCR) (2012). 'Robot Fish', http://www.expo21xx.com/automation21xx/14927_st3_university/ retrieved on April 26, 2012. 
Human Centered Robotics Group at Essex (2010). http://dces.essex.ac.uk/staff/hhu/HCRGroup.html retrieved on February 30, 2010.

Klasen, H.J. (2000). A historical review of the use of silver in the treatment of burns. II. Renewed interest for silver. Burns, 26, p. 131-138.

Mail Online (2008). Pictured: The robot that can pull faces just like a human being, http://www.dailymail.co.uk/sciencetech/article-1085059/Pictured-The-robot-pullfaces-just-like-human-being.html retrieved on May 3, 2012.

Mashable Tech (2012). 35-Foot Robot Snake Weighs a Ton, Causes Nightmares. http://mashable.com/2011/11/16/35-foot-robot-snake/ retrieved on April 29, 2012.

Mucha, H., Hoefer, D. and et al. (2002). Antimicrobial finishes, modifications, regulations and evaluation, Melliand, 4, p. 238-243.

NDTV (2010). Students, meet your new teacher, Mr. Robot. http://www.ndtv.com/article/sci-tech/students-meet-your-new-teacher-mr-robot36799 retrieved on May 2, 2012.

PHYS.ORG (2011). It's a bird, it's a plane, it's a robot bird. http://phys.org/news/2011-03bird-plane-robot-video.html retrieved on May 2, 2012.

Seattle Education (2010). Lessons from http://seattleducation2010.wordpress.com/tag/teaching/ retrieved on March 20, 2012.

Shneiderman, Ben. (1997). Designing the User Interface, Longman Third edition, page 21.

Stillman, M.J. et al. (1994). Spectroscopic studies of copper, silver and gold metallothioneins, Metal-Based Drugs, 1, p. 375-394.

Technology Review: Published by MIT (2007). Robotic Insect Takes Off. http://www.technologyreview.com/computing/19068/ retrieved on April 27, 2007.

The Indiana Gazette (2009). Human-like robot smiles, scolds in Japan classroom. http://www.indianagazette.com/b_entertainment/article_fec68350-03ec-5b89-821f920198a154f3.html retrieved on May 22, 2009.

The New York Times (2010). Students, Meet Your New Teacher, Mr. Robot. http://www.nytimes.com/2010/07/11/science/11robots.html?pagewanted=all retrieved on April 29, 2010.

Tutgun (2009). Study on the Robot Technologies Used in the Intelligent Systems Integration in Different Areas of the Nanotechnology, 5th National Nanoscience and Nanotechnology Conference, Anadolu University Publication No: 1906, İleri Teknolojiler Araştırma Birimi Yayınları [Advanced Technologies Research Unit Publications], No:1, Page 348. 
UCSanDiego (2008). Machine Perception Lab Seeks to Improve Robot Teachers with Intelligent Tutoring Systems. http://ucsdnews.ucsd.edu/newsrel/general/0708RobotTeachers.asp retrieved on June 10, 2008.

Ureyen, M.E., Çavdar, A. and et al. (2009). Antibacterial Efficacy and Laundering Durability of Textile Fabrics Treated by Silver Doped Nano Scaled BioAntimicrobial Finishing Agent, 5th National Nanoscience and Nanotechnology Conference, Anadolu University Publication No: 1906, İleri Teknolojiler Araştırma Birimi Yayınları [Advanced Technologies Research Unit Publications], No:1, Page 408.

Voice of America (2011). South Korean Students Learn English from Robot Teacher. http://www.voanews.com/english/news/asia/South-Korean-Students-LearnEnglish-from-Robot-Teacher-117640783.html retrieved on May 5, 2012.

Yağcizeybek, S. (2008). Using Nanotechnology in the field of medicine. http://www.biymed.com/yazar.asp?yaziID=287 retrieved on May 27, 2009. 